\title{
Study on How to Promote Industrial Design in Equipment Manufacturing Industry Based on Design Management Perspective
}

\author{
Yu Chen \\ School of Design \\ South China University of Technology \\ Guangzhou, China 510640
}

\author{
Guangxiong Liu \\ School of Design \\ South China University of Technology \\ Guangzhou, China 510640
}

\begin{abstract}
As an important approach to promote the upgrade of manufacturing industry, Industrial design has proved its value in the traditional consumer industry but kept slow in the equipment manufacturing due to all kinds of obstacles and causes. Based on perspective of design management, this paper makes detailed analysis of the differences inside so as to analyze the characteristics and relevant problems of industrial design in equipment manufacturers. And then suggestions to upgrade product design in equipment manufacturing are proposed from different perspectives of government, manufacturing enterprises and design companies.
\end{abstract}

Keywords-equipment manufacturing industry; industrial design; design management

\section{INTRODUCTION}

In recent years, China has made great achievements in the design field, and the industrial size and influences are expanding around the world. However deep analysis show that even though we have developed at lot in manufacturing and design, yet facing different manufacturing industries, the design is in a serious imbalance: the innovative design related to production and application is focused on the daily used products industry such as household appliances, communications, digital and so on, yet there are inadequate innovative design in equipment manufacturing, hardware and the like. Therefore, it is necessary to conduct studies on ways to introduce and promote the design in the equipment manufacturing so as to seek a long-term development of the industry.

The current studies of industrial design on equipment manufacturing are mostly focused on product brand images, product design language, and man-machine design. This article will analyze the problems faced by the industrial design of equipment manufacturing in the perspective of design management, comparing the differences of daily used products enterprises and equipment manufacturers in the product development so as to analyze the characteristics of

Fund Project: Guangdong Province Soft Science Project (2012B070300090), Guangdong Provincial Department of Education Project (2012WYM_0013). The Fundamental Research Funds for the Central Universities South China University of Technology (D2156350). product design relative to the equipment manufacturing as well as its influences on the design, then ways to upgrade the equipment manufacturing product design are raised from perspectives of governments, manufacturers and designers.

\section{IMPORTANCE OF INDUSTRIAL DESIGN IN PRODUCT DEVELOPMENT OF EQUIPMENT MANUFACTURING}

Industrial design plays an important role in shaping brand images for the manufacturing. No doubt the equipment from the equipment manufacturing are the master for the chain of the whole manufacturing, yet obvious comparison can be found between foreign products with reliable quality and top images and domestic products with lower prices and low quality, as a result most of the equipment manufacturers at home develop at a low speed with products attracting less eyeballs. In recent years, going with the development of industrial design at home, it has been a trend to shape brand images through the design so as to promote product innovation, for example, commercial giants as Haier, Huawei, Midea and so on all take the design as an important way to build a competitive advantage. Yet we must see that those which value design management and carry out successfully are mostly daily used products enterprises. Yet except few giants which own such awareness in the equipment manufacturing, most have not taken measures to introduce the design for products. It can be said that most have no clear understanding of the design or are vague at it

Industrial design has a positive effect on the development of equipment manufacturing enterprises. Some mechanical experts ever thought that golden decade for the construction machinery industry in China had passed, nowadays, with the technology homogenization, to take the design as a breakthrough point to enhance the strength of enterprises is a new path feasible. Seen internationally the competition in the equipment manufacturing has been transited to market demand from technique and functions and been hot in the design, which cannot be reversed. The equipment manufacturing in China has to grasp the development orientation and value the upgrade of technique, function, marketing, management and design in order to get rid of the single technical index competition mechanism and the extensive growth mode and occupy market shares in the 
global manufacturing. Enterprises are encouraged to upgrade the overall product quality through industrial design, showing the product grades and sense of value so as to get recognized by professional users and loyalty.

\section{Characteristics OF DESIGN IN PRODUCT DEVELOPMENT OF EQUIPMENT MANUFACTURING}

This section compares the differences between daily used products enterprises and equipment manufacturers in new product development so as to analyze the characteristics of the equipment manufacturers as well as its influence on the design.

\section{A. End Users}

Compared to the equipment manufacturing, the products of the daily used products enterprises are directly related to users, generally the buyers that they face will be the product end users, which are close to daily life and the design will offer direct service to users. The daily used products enterprises that value the design will not only set special design departments for the design innovation, product research and development but also authorize some projects of their own to a third designer to design so as to perfect the product development and innovation of their own. The design of such industries has created a set of scientific and efficient methods for user research and innovation. The userbased innovative methods bring soils for the design service to grow in the industries, with the manufacturing development, the design service will form a set of comparatively perfect design development and management experience, which work well when cooperating with the manufacturing.

Yet buyers the equipment manufacturing faces are enterprises rather than product users. The difference determines that when studying users, the designer has to distinguish users from customers. What the designers need to study shall not only include requirements on products from users but also customers' demand for the products. Actually only the customers' demands are considered while ignoring the user's demand for the product. As a result, the users' needs are not effectively offered, which eventually hinders the development and innovation of the design in the equipment manufacturing.

\section{B. Nature of the Industry}

First of all, the equipment manufacturing has a very long research and development cycle, where the technologies concerned are highly difficult, structure-complicated and involving diverse disciplines [1]. Accordingly the enterprises pay more attentions to technical innovation than the design innovation, besides, it has higher requirements in the technical complexity and advancement. For the daily used products enterprises, the maturity of the industry leads to little difference in basic technologies, so the enterprises will much value user experience, based on which product's new functions are developed. The equipment manufacturing is focused on the reliable product functions, and priorities will be given to technologies for the product research and development, and technological innovation is expected to create value.

Second, considering the characteristics of equipment manufacturing, technologies owned by the enterprises are also barriers for design companies and designers. On the one hand, the design companies will be difficult to understand or participate in the whole process of product development just like the daily used products. On the other hand, due to the special technologies existing in the industry, the design companies are required to have some technical reserves when designing the equipment manufacturing products, which is also a reason causing it difficult for the design to be integrated to the equipment manufacturing.

\section{Design Awareness}

The above shows the importance of equipment manufacturing enterprises which value technical innovation but ignore the design innovation, which is traditionally a misunderstanding. A considerable number of enterprises still hold the idea that the design innovation is mainly appearances and shapes, thinking that the design brings no technical renovation but a renewal in appearance. Many equipment manufacturing enterprises know nothing about the goal of industrial design which are to plan the coming work mode and living style, and its max value is the transformation of creative thoughts, for which the products are carriers[2]. Actually what the equipment manufacturing product can be done upon is more than shapes, there are also designs in operation mode, structural layout optimization, technical achievement application and so on. Once a point mentioned above is broken through, the value it brings will be beyond greatly the value that single shapes can bring.

\section{Material and Processing Technology}

Seen from the perspective of design only, there is an obvious contrast between the equipment manufacturing which has special purposes in the material selection and process and the daily used products manufacturing which has general purposes. Due to the lowered technical threshold for material selection, the daily used products enterprises gradually form a generally in the trade, and the selection of materials and its processing can be made freely within a scope. However, in most cases, the products of equipment manufacturing will be used in special circumstances such as high temperature resistance, dirt resistance, wear resistance and so on there will be more requirements on material properties, as a result, there will be a smaller scope for selection materials for the design compared to traditional products.

For the special purposes of equipment bring some barriers for the design innovation, so generally the design plan shall consider the points such as processing technologies and so on and chance the initial design philosophy according to the requirements of manufacturers and owners[3]. Modeling requires that the designer should not only be capable of aesthetics but also deeply understand the material, structure and processing, and the special purposes of the materials lead to the restriction on the freedom to design during the product research and 
development. Besides, the whole system of equipment is much complicated, so is the material selection. For designers, it is necessary to rebuild a reserve of knowledge relative to materials and processing technologies, as a result, the barrier formed by such reserves of knowledge cause many designers just consider about form of product in design, while failing to carry out deep-level innovation.

TABLE I. COMPARISON BETWEEN TRADITIONAL DAILY USED PRODUCTS ENTERPRISES AND EQUIPMENT MANUFACTURING ENTERPRISES IN INDUSTRIAL DESIGN

\begin{tabular}{|c|c|c|}
\hline & $\begin{array}{c}\text { Daily used products } \\
\text { enterprises }\end{array}$ & Equipment manufacturing \\
\hline End users & $\begin{array}{l}\text { Customer }=\text { User } \\
\text { User is a product user and } \\
\text { buyer, and the design has a } \\
\text { thorough and standard } \\
\text { method to study users. }\end{array}$ & $\begin{array}{l}\text { Customer } \neq \text { User } \\
\text { User is a product but } \\
\text { generally not the buyer, } \\
\text { generally the customer is an } \\
\text { organization or enterprise, } \\
\text { and the design introduction } \\
\text { shall consider the difference } \\
\text { and factors between } \\
\text { customers and users. }\end{array}$ \\
\hline Type & $\begin{array}{l}\text { Driven by user need, the } \\
\text { design can participate in } \\
\text { the product and technical } \\
\text { research and development, } \\
\text { where there are few } \\
\text { barriers. }\end{array}$ & $\begin{array}{l}\text { Technical innovation, the } \\
\text { design is hard to get involved } \\
\text { in the product research and } \\
\text { development, high barriers } \\
\text { existing. }\end{array}$ \\
\hline $\begin{array}{l}\text { Design } \\
\text { Awareness }\end{array}$ & $\begin{array}{l}\text { Stress user need and } \\
\text { product experience, and } \\
\text { the design is an important } \\
\text { driving factor for product } \\
\text { development. }\end{array}$ & $\begin{array}{l}\text { Stress technical innovation, } \\
\text { technical is taken as root for } \\
\text { the enterprise development, } \\
\text { and the design is thought } \\
\text { applicable only for } \\
\text { appearance innovation. }\end{array}$ \\
\hline $\begin{array}{l}\text { Material } \\
\text { Process }\end{array}$ & $\begin{array}{l}\text { Low requirements in } \\
\text { material and process, wide } \\
\text { space to choose, general } \\
\text { for the industry, and low } \\
\text { threshold for the design } \\
\text { introduction. }\end{array}$ & $\begin{array}{l}\text { High requirements in } \\
\text { material and process, less } \\
\text { space to choose, special } \\
\text { purpose in the industry, and } \\
\text { higher threshold for the } \\
\text { design introduction. }\end{array}$ \\
\hline
\end{tabular}

\section{SUGGESTIONS FOR INDUSTRIAL DESIGN PROMOTION ON THE BASIS OF DESIGN MANAGEMENT}

Through the comparison in end user, enterprise type, design awareness and material processing between equipment manufacturing and daily used product enterprises mentioned above, this article reveals reasons for the inadequate use of design in the equipment manufacturing. Based on the design management, the ways to promote the equipment manufacturing development and enterprise innovation from macro perspective (management departments) and micro perspective (enterprises) are discussed to promote the equipment manufacturing design and enterprise innovation.

\section{A. Ways of Promotion for Macro Management}

1) Strengthen the construction of relevant platforms for industrial design of equipment manufacturing.

First of all, administrative authorities (such as governmental agencies, productivity promotion center, industrial associations and so on) can build a platform through which a design company connects with an equipment manufacturing enterprise. On the one hand, the platform may strengthen the understanding of the equipment manufacturing enterprises of industrial design, collect scattered design resources and make full efforts to serve the equipment manufacturing [4]; on the other hand, large equipment manufacturing enterprises can grasp the market orientation more accurately, working as a leader, besides, the medium and small manufacturing enterprises can also find applicable design service enterprises according to conditions of their own so as to upgrade their products to the maximum.

Second, it needs to strengthen the construction of platforms relative to common technologies and knowledge base for the equipment manufacturing. And corresponding database can be set up through leading by governments and supports by enterprises on the basis of local advantages in resources. The databases established will standardize the design and manufacturing standards for the whole industry, providing necessary foundation for smooth implementation of design and reduce barriers of technology effectively. in addition, the knowledge base can effectively used to reuse knowledge, shorten the time for R\&D and improve the design quality [5]. At last, it is suggested to create a user experience innovation platform for the design upgrade of equipment manufacturing product, which may borrow the experience, methods and means that traditional daily used products enterprises adopt for innovation so as to provide user research resources in all aspects for the equipment manufacturing.

Specific measures should be first focused on policies, the government can release relevant policies to support construction of such platforms; Second, the government can cooperate with leading enterprises of the industry to create relevant industrial standards and evaluation system; finally, with the combination of production, study and research, the platform can be improved gradually.

\section{2) Benchmarking enterprises}

It means that leading enterprises shall be selected in the industry of equipment manufacturing, build industrial design mode projects and mode enterprises, set models for the industry so as to lead the design and improve traditional awareness. For example, CRRC Corporation Limited has made great achievements that have amazed the world, China high speed railway has opened an international market successfully, during the course, the industrial design has played an important role. Jan 2015, CRRC Corporation Limited was approved as State-Level Industrial Design Center by Ministry of Industry and Information Technology, which fully showed the roles and achievements of the design to the equipment manufacturing. Relying on the existing design resources, CRRC Corporation Limited was granted about ten industrial design awards such as China Design Red Star Award, China Appearance Design Excellent Award and so on. On the one hand, the success of CRRC Corporation Limited in design has greatly improved the images of Chinese manufacturing abroad, bringing huge economic benefits. On the other hand, it sets a model for the industry, showing the role of the design introduction to the equipment manufacturing. What it brings are not only the value and opportunities to enterprises, what is important is it explores a 
way feasible for other enterprises, which plays a model role in changing the misunderstanding of medium and small equipment manufacturing enterprises "Fig. 1".
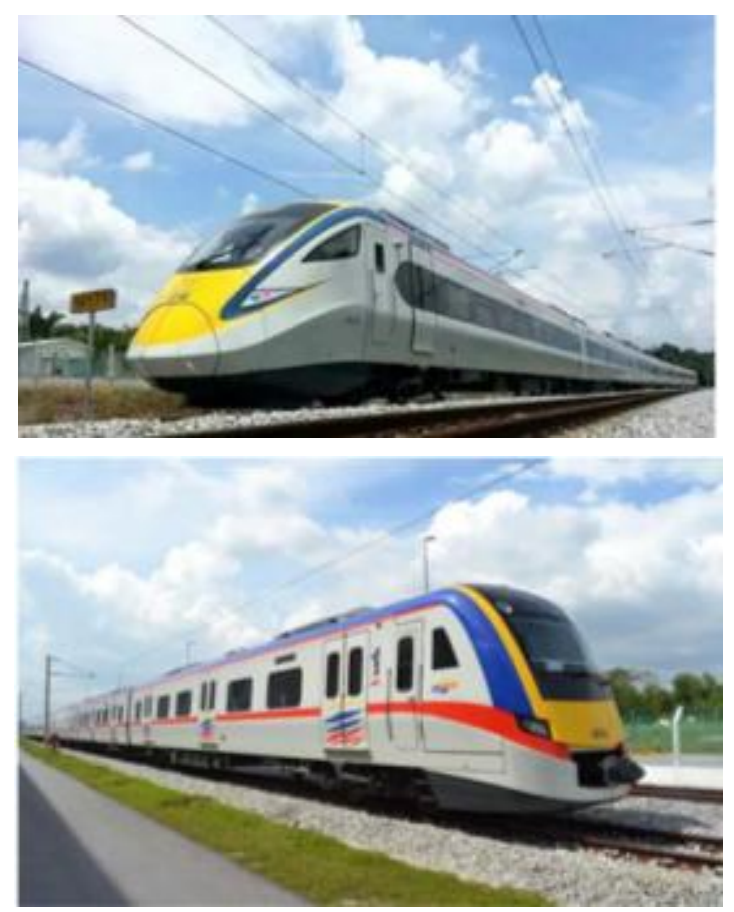

Fig. 1. Products of CRRC Corporation Limited.

Source: Online search

\section{B. Ways of Promotion for Enterprises}

1) Equipment manufacturing enterprises: For large equipment manufacturing enterprises, what they need to do is to strengthen the experience-based innovation, emphasize the emotional design, pursuing the user experience-based integration of technology and design philosophy. The large enterprises have made great achievements in the brand shaping, product language, human relations and user experience, under such situations, what the enterprises should do is to lead the development orientation of the industry. As far as the design, what we need to consider is how to make use of the design to show and develop the added value of technology, for example, screen touch technology has appeared for decades, before it is applied on the mobile phone by Apple Inc, the technology is of limited value, but after being designed, the technology immediately shows some effects unimaginable. So what the large equipment manufacturing enterprises should consider is how to deeply integrate the design and technologies.

What medium and small equipment manufacturing enterprises need to consider is to change traditional concepts, give more consideration to the shaping of brand images and modeling languages as well as human relations. Set up brand features of them and strengthen the market competitiveness, which are crucial for the medium and small enterprises, perhaps it cannot achieve the breakthrough effect like large enterprises, yet it works well for the construction of infrastructures of their own. In the meantime, it is also important to keep up with the user experience to improve the existing human relations of products, only the needs of the people are considered can the products create greater value and bring a long-term development for the enterprise brands.

2) Design companies: As for the cooperation modes between industrial design organizations and manufacturing enterprises, Yuan Hefa and Ding Wei raise four levels for traditional design service, that is, form, image, need and experience[7]. They divided the manufacturing enterprises relative to the design service into four types, that is, track, brand, innovation and experience. Therefore, when having design introduction to the equipment manufacturing enterprises, design companies shall also distinguish the properties, adopting diverse service modes for different enterprises. When serving large manufacturing enterprises, it shall adopt need and experience-based service mode. Specifically what design companies should do is to see through hearts of consumers, study the experience of users so as to guide the product $R \& D$ orientation in the enterprises. Besides, based on the experience mode, it also needs to exert the leading roles of large enterprises, develop and explore products in the future and seek the new industrial orientation. When serving medium and small enterprises, what design companies shall do are form and image. Through the form and image mode, design companies may get more visual effect and direct influence to the enterprises.

In addition, when expanding business in the equipment manufacturing, what the design enterprises need to do is to understand the differences between equipment manufacturing and traditional industries, besides, the equipment manufacturing industry needs to be subdivided. For design companies, the equipment manufacturing enterprises will be a great blue ocean market, where there are more opportunities compared to the traditional household appliance market. However, they should also be aware of the problems accumulated of their own as well as the differences between equipment manufacturing enterprises and traditional daily used products enterprises, on which, clear understanding must be kept. Take New Plan design company as an example, a design research institute was established in order to provide better services to the mechanical industry, offering market analysis, user studies and strategic design service for mechanical customers. Rely on research-based design and scientific product line planning to create value, enhance the brand and product competitiveness. The Guantai industrial endoscope shows how professional it is. According to the person in charge, the product, from early handheld mode research to the mid-term foam mode, all undergo repeated adjustment and verification. Each component is considered for its special scene for use, for example, the screen adopts special edge wrapping design to avoid damages due to the screen drop, it is designed for waterproof, dustproof and quick disassembly, with an appropriate $105^{\circ}$ rocker angle much easier to operate and so on. Through deep design research, it not only succeeds in improving the sense of value of Guantai products, but also gets internationally accepted, winning the 2016 red dot design award "Fig. 2". 

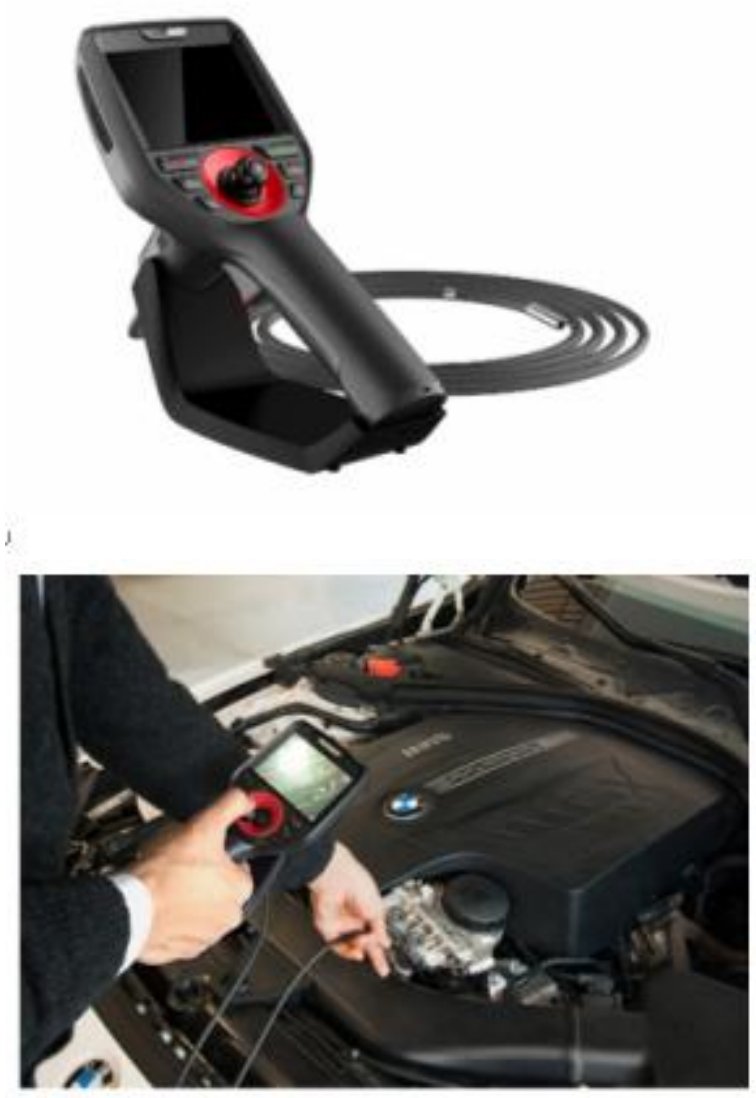

Fig. 2. Guantai Industrial Endoscope.

Source: http://www.newplan.com.cn/index.php/page-18-182.html

The cooperation between New Plan Company and equipment manufacturing enterprises show, when serving the equipment manufacturing, the design enterprises have to accumulate relevant technologies and knowledge before conducting design research according to the product characteristics in order to adopt design approaches to reach the design effect as expected.

\section{CONCLUSION}

Currently the transformation and upgrade of manufacturing industry have become a necessity, and no doubt, the design is a power to promote the development of the whole industry. Industrial design has proved its value in the traditional consumer industry but kept slow in the equipment manufacturing due to all kinds of obstacles and causes. Facing such phenomenon, this article makes detailed analysis of the differences inside and raises suggestions and ideas from management, hoping to break the dilemma that the design faces in the equipment manufacturing. Relevant analysis and suggestions are stated here from the macroperspective, and more studies will be done on the micro level in the future.

\section{REFERENCES}

[1] Yu Suihuai, Design Though and Industrial Design in Equipment Manufacturing [J]. Design, 2015,09: 156-157.

[2] Dong Qi; Zhou Yun; Zhang Fan; Cao Xinwen. Appearance Design of Construction Machinery Viewed from Industrial Design[J]. Construction Machinery and Equipment, 2012, 03: 53-56.

[3] Xiong Ying-jun. Analysis on Development of Chinese Equipment Manufacturing Industry and Industry Design[J].Packaging Engineering, 2008,11: 217-218.

[4] A Research on the Establishment of the Industrial Design Networking Service Platform for Small and Medium Enterprises in Changsha/Zhuzhou/Xiangtan[D]. Hunan: Hunan University,2009.

[5] Zhang Shouxue, Yan Bo, Gao Dongjie, Researches on Methods to Build Knowledge Database of Industrial Design of Electric Tools[J]. Computer CD Software and Applications, 2013,24: 28-29.

[6] Wang Lijun, Lu Lijun, Predication of Key Common Technologies and R\&D Strategies for Equipment Manufacturing in Zhejiang Province [J]. Journal of the Party School of CPC Ningbo Municipal Committee, 2011, 02: 97-102

[7] Product Design Strategy in Diversified Market Demand[J].Journal of Dong Hua University (Natural Science), 2011.37(4):514-517. 